\title{
A Benzyl Alcohol Derivative of BDPA Radical for Fast Dissolution Dynamic Nuclear Polarization NMR Spectroscopy
}

\author{
J. L. Muñoz-Gómez, ${ }^{a}$ E. Monteagudo, ${ }^{b}$ V. Lloveras, ${ }^{a}$ T. Parella, ${ }^{b}$ J. Veciana, ${ }^{*, a}$ and J. Vidal-Gancedo ${ }^{*}, a$
}

The synthesis, structural characterization and the successful application of a carbon centered radical derived from 1,3bisdiphenylene-2-phenylallyl (BDPA), its benzyl alcohol derivative (BA-BDPA), as a polarizing agent for Dynamic Nuclear Polarization (DNP) are described. The reported BA-BDPA radical meets all the requirements to become a promising candidate for its use in in-vivo DNP-NMR experiments: it is soluble into neat $\left[1-{ }^{13} \mathrm{C}\right]$ pyruvic acid, insoluble in the dissolution transfer solvent and effective as a polarizing agent in fast dissolution DNP-NMR applications, without the need of using glassing agents. Moreover, it enables a simple but effective in-line radical filtration to obtain hyperpolarized solutions of [1- $\left.{ }^{13} \mathrm{C}\right]$ pyruvic acid free of radicals, that offers a better polarization performance.

\section{Introduction}

NMR spectroscopy has become a fundamental analytical technique $^{1}$ widespread used for the identification and characterization of chemical and biochemical molecules in both solution and solid-state conditions, in terms of chemical structure, dynamics, and intra- and intermolecular interactions as well as to the complex mixture analysis. In addition, magnetic resonance imaging (MRI) is one of the best noninvasive clinical imaging methods currently used in medicine. ${ }^{2}$ However, the progress of both NMR and MRI techniques is still limited by their relative poor sensitivities due to the inherent low thermal-equilibrium Boltzmann polarization of some involved nuclear spins, such as ${ }^{13} \mathrm{C}$ and ${ }^{15} \mathrm{~N}$. During the last years, enormous efforts have been devoted to enhance the NMR sensitivity, including the hardware development of cryogenically cooled probes $^{3}$ and the availability of higher magnetic field superconducting magnets. ${ }^{4}$ Other challenging approaches based on the application of hyperpolarization methods on modern liquid-state NMR spectroscopy are an ongoing field of research, namely optical pumping, ${ }^{5,6}$ parahydrogen induced polarization ${ }^{7,8}$ (PHIP) and dynamic nuclear polarization $^{9,10}$ (DNP). In particular, fast dissolution of highlypolarized small molecules combined with $\mathrm{DNP}^{11}$ is one of the most efficient approaches. This technique is based on cooling down a solution sample, usually formed by (i) the analyte, (ii) a glassing solvent agent and (iii) a radical (typically a trityl radical), into a high magnetic field $(3.35 \mathrm{~T})$. Under such conditions and applying microwave irradiation at an appropriate frequency of the radical resonance, the strong polarization of unpaired electrons on free radical molecules, homogeneously distributed within the solution, can be transferred to nearby nuclei of the analyte. Then, the hyperpolarized frozen solution is automatically dissolved into a warm solvent (water or methanol) and quickly transferred to the NMR spectrometer, where the enhanced signals from the analyte must be quickly detected by conventional NMR techniques. Just to mention a few examples, fast dissolution DNP studies has been successfully reported in several in vitro and in vivo applications as, for instance, for structural elucidation, ${ }^{3,12}$ to monitor chemical and biochemical reactions, ${ }^{13,14}$ to study molecular interactions, ${ }^{15}$ to develop new and ultrafast NMR experiments, ${ }^{16,17}$ to perform in vivo ${ }^{13} \mathrm{C}$ imaging of metabolic reactions ${ }^{2,18,19}$ or looking for new biomarkers by real-time molecular imaging. ${ }^{11,20,21}$

Currently, the water-soluble trityl-based stable free radical $\mathrm{OX}^{22}$ (structure not shown) is the most frequently used polarizing agent in dissolution DNP for low- $\gamma$ nuclei such as ${ }^{13} \mathrm{C}$ or ${ }^{15} \mathrm{~N}$, mainly because it presents a narrow electron paramagnetic resonance (EPR) linewidth, which is among the narrowest linewidths found in free radicals. This narrow linewidth translates into a low electron heat capacity and yield a lower spin temperature for the electron spin-spin interaction reservoir that is in thermal contact with the nuclear Zeeman system. Alternatively, nitroxide-based radicals and biradicals ${ }^{23}$ present a wider EPR linewidth and, as a consequence, DNP of nitroxide doped ${ }^{13} \mathrm{C}$ substrates, which also proceeds predominantly via thermal mixing, yields a relatively lower polarization. Recently, BDPA radical (Fig. 1), which has comparable linewidth to OX63, has been demonstrated to be a versatile polarizing agent under a variety of conditions, ${ }^{24}$ from solid-state DNP experiments ${ }^{25}$ to fast dissolution DNP of [1${ }^{13}$ C]pyruvic acid. ${ }^{26}$ In the latter case, although the residual BDPA radical traces can be removed from the hyperpolarized solution by filtration, its insolubility into neat $\left[1-{ }^{13} \mathrm{C}\right]$ pyruvic acid requires the use of sulfolane as a glassing agent, hampering its application to in-vivo experiments. 
Herein we present the synthesis of a novel benzyl alcohol derivative of the BDPA (BA-BDPA, 8) which is a carboncentered free radical soluble in $\left[1-{ }^{13} \mathrm{C}\right]$ pyruvic acid. The DNP sample preparation conditions are similar to those for OX63 which do not require glassing agents. Besides, it is shown that the residual traces of BA-BDPA radical can be rapidly removed during the transfer process, as in the case of the nonfunctionalized commercially available BDPA, becoming a promising polarizing agent for fast dissolution DNP-enhanced in vivo applications.

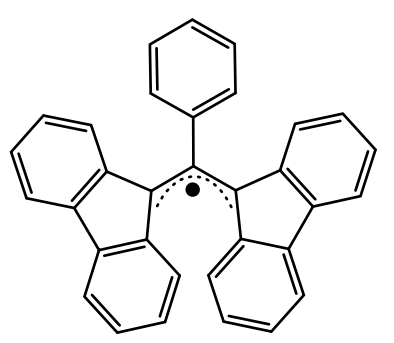

1,3-bisdiphenylene-2-phenylallyl (BDPA)

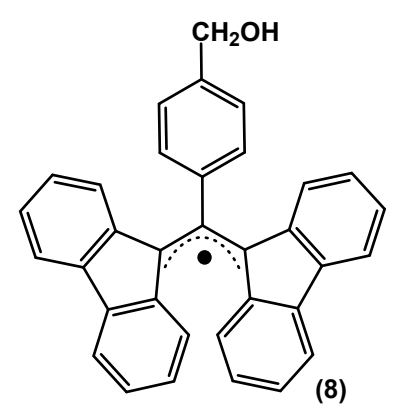

BA-BDPA
Fig. 1 Structures of BDPA and BA-BDPA free radicals.

\section{Material and methods}

1,3-bisdiphenylene-2-phenylallyl (BDPA) radical/benzene clathrate $(1: 1),\left[1-{ }^{13} \mathrm{C}\right]$ pyruvic acid, sulfolane and all the solvents were purchased from Sigma-Aldrich Company, Ltd. (Tres Cantos, Madrid, Spain) and were used without further purification.

\section{X-band EPR}

The EPR spectra (see ESI, Fig. S1) were recorded at room temperature, in THF (HPLC quality) using a Bruker ELEXYS E500 X-band spectrometer equipped with a field-frequency (F/F) lock accessory and built in NMR Gaussmeter. A rectangular (TE 102) cavity was used for the measurements.

\section{Dynamic Nuclear Polarization}

Sample preparations: (a) BDPA solutions: As described previously, ${ }^{26} 4.0 \mathrm{mg}$ BDPA were completely dissolved in 100 $\mu \mathrm{l}$ of sulfolane, then $100 \mu \mathrm{l}$ of $\left[1-{ }^{13} \mathrm{C}\right]$ pyruvic acid were added up to achieve a final sample concentration of BDPA of $40 \mathrm{mM}$. (b) Radical $\mathbf{8}$ solutions: $1.8 \mathrm{mg}$ of $\mathbf{8}$ were completely dissolved into $100 \mu \mathrm{l}$ of $\left[1-{ }^{13} \mathrm{C}\right]$ pyruvic acid and $0.36 \mu \mathrm{l}$ of benzene were added. The final concentration of both BA-BDPA 8 and benzene was $40 \mathrm{mM}$. The same procedure was followed to obtain all sample solutions of $\mathbf{8}$ at different concentrations (20, 60 and $80 \mathrm{mM}$ ). (c) OX63 solutions: $2.4 \mathrm{mg}$ OX63 were completely dissolved in $100 \mu \mathrm{l}$ of $\left[1-{ }^{13} \mathrm{C}\right]$ pyruvic acid yielding a final concentration of OX63 of $15 \mathrm{mM}$.

DNP experiments: Aliquots of $20 \mu \mathrm{l}$ were polarized using the HyperSense ${ }^{\circledR}$ (Oxford Instruments Molecular Biotools, Oxford, UK) commercial polarizer working at $3.35 \mathrm{~T}, 1.4 \mathrm{~K}$. Samples were polarized for approximately 90 minutes irradiating at the frequency of the corresponding optimum positive peak $\mathrm{P}(+)$, determined by ${ }^{13} \mathrm{C}$ microwave sweep spectrum. The hyperpolarized sample was then dissolved with $4 \mathrm{ml}$ water and automatically transferred $(10 \mathrm{~s})$ into an empty NMR tube placed inside a Bruker AVANCE-III $600 \mathrm{MHz}$ spectrometer (Bruker Biospin, Rheinstetten, Germany), previously locked and shimmed with a reference sample. The spectrometer was equipped with a $5 \mathrm{~mm}$ broadband TXI inverse probehead incorporating a z-gradient coil and working at field strength of 14.1 $\mathrm{T}\left(600.13\right.$ and $150.03 \mathrm{MHz},{ }^{1} \mathrm{H}$ and ${ }^{13} \mathrm{C}$ frequencies respectively). After dissolution, the polytetrafluoroethylene (PTFE) transfer pipe line was cleaned with $3 \times 4 \mathrm{ml}$ methanol and $3 \times 4 \mathrm{ml}$ water, see the ESI.

Liquid-state ${ }^{13} \mathrm{C}$ DNP-NMR measurements: The ${ }^{13} \mathrm{C}$ DNPNMR spectra were acquired $10 \mathrm{~s}$ after the sample dissolution using a conventional 1D broadband, heterodecoupled ${ }^{13} \mathrm{C}$ spectrum was recorded employing a $90^{\circ} \mathrm{RF}$ pulse. The data were collected into $32 \mathrm{~K}$ data points during an acquisition time of $0.43 \mathrm{~s}$ and using a spectral width of $37878 \mathrm{~Hz}$ in a single scan. After Fourier transformation, the frequency-domain spectra were then manually phased and baseline corrected.

After complete decay of polarization, a conventional $1 \mathrm{D}{ }^{13} \mathrm{C}$ NMR thermal equilibrium spectrum was acquired with an acquisition time of $0.47 \mathrm{~s}$ and a recycle delay of $2 \mathrm{~s}$. The data were collected into $32 \mathrm{~K}$ data points, with a spectral width of $34722 \mathrm{~Hz}$ and as the sum of 32 transients using a $30^{\circ}$ degree flip angle, unless otherwise stated.

The liquid-state enhancements were calculated, as described previously, ${ }^{27}$ by the division of the signal intensity of the hyperpolarized signal over the intensity of the thermal equilibrium signal multiplied by the square root of the number of scans.

\section{Results and discussion}

The synthesis of BDPA carboxylic acid 6 (see ESI) is shown in Scheme $1 .{ }^{28}$ This multistep synthesis consisted on a condensation between fluorene and 4-carboxybenzaldehyde followed by a double bond bromination to obtain compound 4 . The latest step was improved by changing the previously reported reaction conditions: in $\mathrm{CCl}_{4}$ and for only five minutes (Y: $88 \%$ ). The next steps were the elimination of hydrogen bromine, which generates compound $\mathbf{5}$, and, finally, the allylic substitution which adds the final fluorene ring that completes the BDPA structure. The reduction reaction of the carboxylic group of 6 to the corresponding benzyl alcohol 7 was performed with diisobutylaluminium hydride (DIBALH) in excess. The acid reduction without anion formation was possible because of the big size of this reducing agent. This process could be naked-eye controlled by the absence of the typical blue colour corresponding to the BDPA anion. Finally, radical $\mathbf{8}$ was isolated by the treatment of the benzilic alcohol derivative with 1,8-diazabicycloundec-7-ene (DBU) followed by $\mathrm{AgNO}_{3}$ as an oxidant agent in dichloromethane (DCM). The total yield of the synthesis of 8 was $40 \%$. 


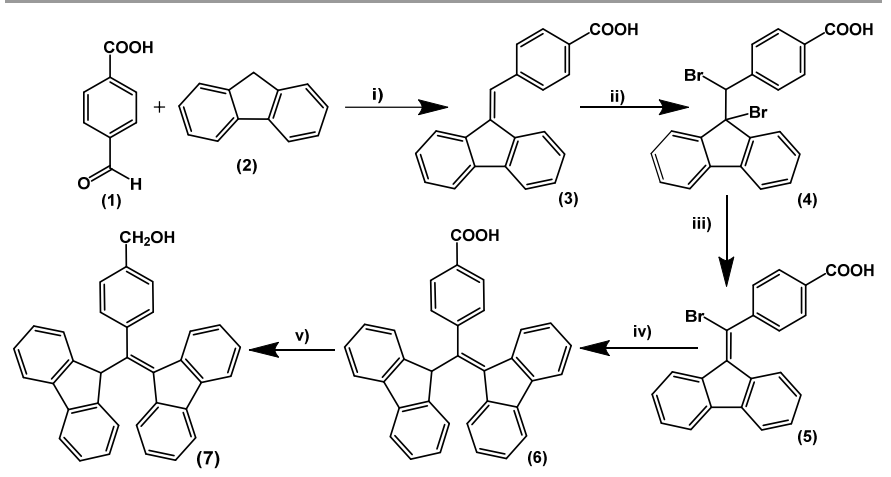

Scheme 1 Synthesis of free radical 8. Conditions: i) tBuOK, EtOH, reflux 16 h.; ii) $\mathrm{Br}_{2}$ in $\mathrm{CCl}_{4}$, room temperature, 5 min.; iii) $\mathrm{NaOH}$ in $\mathrm{EtOH}$, reflux, 30 min.; iv) Fluorene, tBuOK in DMA room temperature, 1 h.; v) DIBALH, anhydrous THF, room temperature, $16 \mathrm{~h}$.; vi) $\mathrm{DBU}$ in $\mathrm{DCM}$, then $\mathrm{AgNO}_{3}$.

The DNP experiments were carried out using freshly prepared solutions of radical 8 in $\left[1-{ }^{13} \mathrm{C}\right]$ pyruvic acid. ${ }^{\xi}$ The microwave sweep or ${ }^{13} \mathrm{C}$ microwave DNP spectrum (Fig. 3) shows the ${ }^{13} \mathrm{C}$ NMR signal intensity against the microwave irradiation frequency of $40 \mathrm{mM}$ solution of BDPA and BA-BDPA radical. The optimum positive $\mathrm{P}(+)$ and negative $\mathrm{P}(-)$ peaks were determined for both samples by scanning from 94.000 to $94.200 \mathrm{GHz}$ during 3 minutes at each frequency every $5 \mathrm{MHz}$. The optimum $\mathrm{P}(+)$ was set at 94.077 and $94.087 \mathrm{GHz}$ for BDPA and $\mathbf{8}$, respectively. The separation between positive and negative polarization peaks $|\mathrm{P}(+)-\mathrm{P}(-)|$ for BDPA and $\mathbf{8}$ was of 50 and $30 \mathrm{MHz}$, respectively. These close values and the comparable EPR linewidths for both radicals, ${ }^{29}$ extracted from the microwave DNP spectra, suggest that the same dominant thermal mixing polarization transfer mechanism, is operative in both cases.

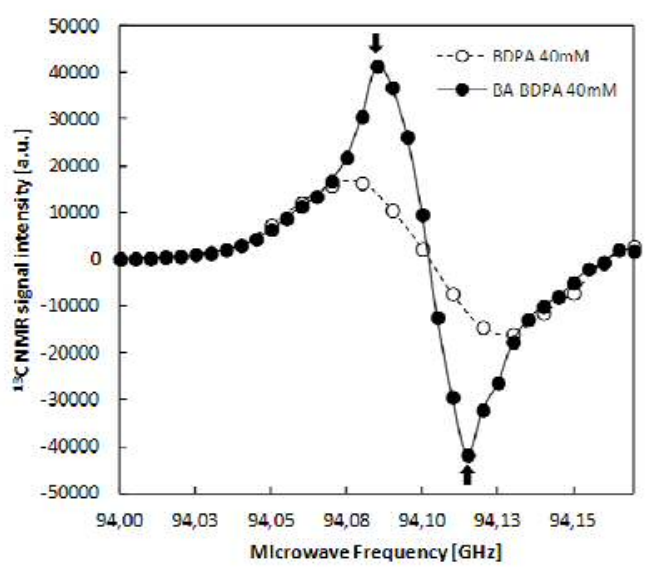

Fig. $3{ }^{13} \mathrm{C}$ microwave DNP spectrum of $50 \mu \mathrm{l}\left[1-{ }^{13} \mathrm{C}\right]$ pyruvic acid doped with 40 $\mathrm{mM} 8$ (solid circles) at $3.35 \mathrm{~T}$ and $1.4 \mathrm{~K}$. The arrows indicate $\mathrm{P}(+)=94.087 \mathrm{GHz}$ and $\mathrm{P}(-)=94.117 \mathrm{GHz}$ polarization peaks, respectively. The microwave sweep spectrum of $50 \mu \mathrm{l}$ of $1: 1(\mathrm{v} / \mathrm{v})\left[1-{ }^{13} \mathrm{C}\right]$ pyruvic acid:sulfolane doped with $40 \mathrm{mM}$ BDPA (open circles) is also shown. It is noteworthy that as the amount of [1${ }^{13} \mathrm{C}$ ]pyruvic acid in the BDPA sample is the half, the intensity of the signal is lower.
In order to determine the optimum concentration of radical 8 to be dissolved in $\left[1-{ }^{13} \mathrm{C}\right]$ pyruvic acid, $20 \mu \mathrm{l}$ sample aliquots with concentrations of $20,40,60$ and $80 \mathrm{mM}$ were polarized at the optimal frequency of $94.087 \mathrm{GHz}$, during approximately 90 minutes (see Fig. S2 in ESI), and automatically transferred to the NMR spectrometer through a home-made in-line filtration system that consists of a high pressure adapter to a syringe filled with cotton (see Fig. S4 in ESI). This filtration completely removed the radical from the dissolution down to $10^{-7} \mathrm{M}$, as confirmed by UV-Vis and EPR spectroscopy (see the final UV-Vis and EPR solution spectra in ESI, Fig. S5).

The optimum concentration of radical 8 found was $40 \mathrm{mM}$ (Fig. $\mathrm{S} 2)$. In Fig. 4 we show the ${ }^{13} \mathrm{C}$ polarization build-up curve for the sample with radical $\mathbf{8}$ in the optimum concentration found and the ones corresponding to BDPA (40 mM) and OX63 (15 $\mathrm{mM}$ ), for comparison. As can be observed in Fig. 4, the $40 \mathrm{mM}$ solution of $\mathbf{8}$ provides better solid-state polarization levels with an important reduction in the polarization time with respect to the BDPA radical, till the half. This can be related with the reduction in the build-up time constant (Tc) which is three times lower. It can also be observed that comparable polarization levels are achieved between 8 and the OX63 trityl radical. The polarizing build-up curves (Fig. 4) were recorded in solid state and the average liquid-state NMR enhancements (ع) were calculated after acquisition of the corresponding thermal equilibrium ${ }^{13} \mathrm{C}$ spectrum (Fig. 5 and Fig. S6). Table 1 shows the liquid-state NMR enhancements measured $10 \mathrm{~s}$ after dissolution of $\left[1-{ }^{13} \mathrm{C}\right]$ pyruvic acid samples doped with different concentrations of the studied radical: $8(20,40,60$ and $80 \mathrm{mM})$, BDPA $(40 \mathrm{mM})$ and OX63 $(15 \mathrm{mM})$. The best polarization for 8 remains the same than in solid state $(40 \mathrm{mM})$, although the time of polarization (and with it the build-up time constant) is not too much longer than in the $60 \mathrm{mM}$ concentration (see Figs. $\mathrm{S} 2$ and $\mathrm{S} 3$ in ESI).

It is worth highlighting that radical $\mathbf{8}$ shows a great advantage in front of OX63 in the transfer process. Indeed, radical 8 is insoluble in the solvent transfer $\left(\mathrm{H}_{2} \mathrm{O}\right)$ and hence it is totally retained in the filtering system (see Fig. S5 in ESI). Thus, the transferred dissolution only contains the hyperpolarized pyruvic acid. By contrast, radical OX63 remains in solution since it is soluble in the solvent used, making faster the relaxation of the hyperpolarized pyruvic acid solution, with the consequent loss of hyperpolarization due to the interaction of the free radical with the hyperpolarized nuclei. ${ }^{26,30,31}$ 


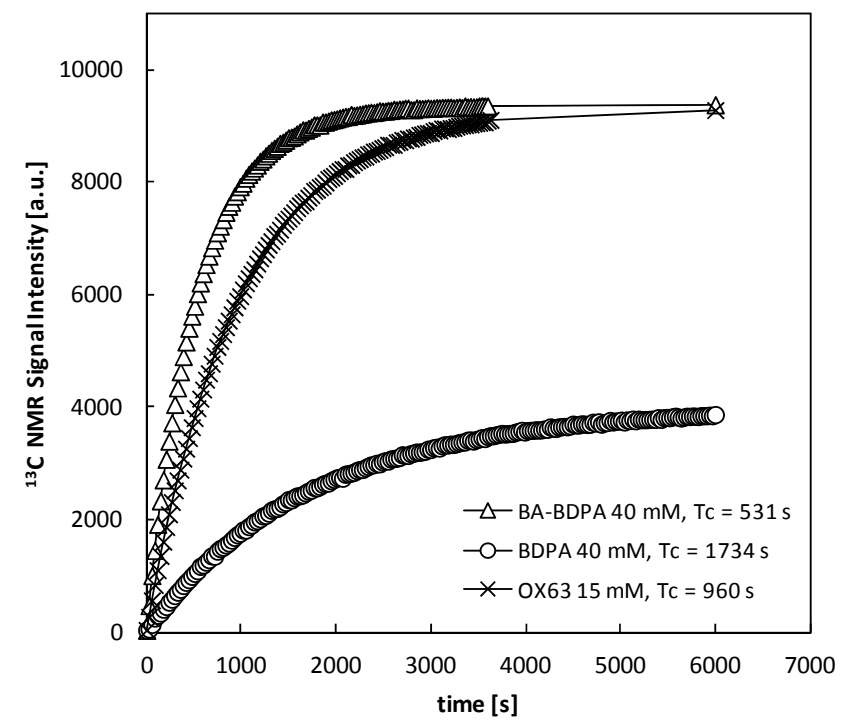

Fig. $4{ }^{13} \mathrm{C}$ polarization build-up curve of $20 \mu \mathrm{l}\left[1-{ }^{13} \mathrm{C}\right]$ pyruvic acid doped with 40 mM 8 (open triangles). The curves of $20 \mu \mathrm{l} 1: 1$ (v/v) $\left[1-{ }^{13} \mathrm{C}\right]$ pyruvic acid:sulfolane doped with $40 \mathrm{mM}$ BDPA (open circles) and $20 \mu \mathrm{l}\left[1-{ }^{13} \mathrm{C}\right]$ pyruvic acid doped with $15 \mathrm{mM}$ OX63 (crosses) are also shown for comparison. It is noteworthy that the amount of $\left[1-{ }^{13} \mathrm{C}\right]$ pyruvic acid in the BDPA sample is half of the others because of its formulation, $\left[1-{ }^{13} \mathrm{C}\right]$ pyruvic acid:sulfolane $(1: 1)$. The polarizing build-up curves are recorded in solid state. The polarization build-up time constants (Tc) are also shown for each corresponding curve.

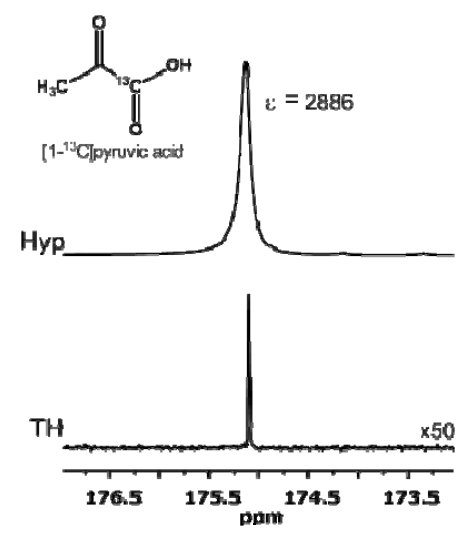

Fig. 5 Hyperpolarized, Hyp, $\left(\theta=90^{\circ}, 1\right.$ scan $)$ and thermal equilibrium, $\mathrm{TH},(\theta=$ $30^{\circ}, 32$ scans) ${ }^{13} \mathrm{C}$ DNP-NMR spectra of $\left[1-{ }^{13} \mathrm{C} 1\right]$ pyruvic acid after filtration. The $\mathrm{TH}$ spectrum is enlarged 50 times.
Table 1 Liquid-state NMR enhancements $(\varepsilon)$ measured $10 \mathrm{~s}$ after dissolution of $\left[1-{ }^{13} \mathrm{C}\right]$ pyruvic acid samples doped with different concentrations of $\mathbf{8}$, BDPA and OX63 radicals.

\begin{tabular}{llll}
\hline Radical conc. (mM) & $\begin{array}{c}\text { Hyperpolarized } \\
\text { compound }\end{array}$ & $\begin{array}{c}\text { Dissolution } \\
\text { solvent }\end{array}$ & $\begin{array}{c}\text { Liquid-state } \\
\text { enhancement }\end{array}$ \\
\hline BA-BDPA $20 \mathrm{mM}$ & {$\left[1-{ }^{13}\right.$ C]pyruvic acid } & Water & 2191 \\
\hline BA-BDPA $40 \mathrm{mM}$ & {$\left[1-{ }^{13} \mathrm{C}\right]$ pyruvic acid } & Water & $\mathbf{2 8 8 6}$ \\
\hline BA-BDPA $60 \mathrm{mM}$ & {$\left[1-{ }^{13} \mathrm{C}\right]$ pyruvic acid } & Water & 2726 \\
\hline BA-BDPA $80 \mathrm{mM}$ & {$\left[1-{ }^{13} \mathrm{C}\right]$ pyruvic acid } & Water & 1387 \\
\hline BDPA 40 mM & {$\left[1-{ }^{13} \mathrm{C}\right]$ pyruvic acid } & Water & $\mathbf{2 4 5 4}$ \\
\hline OX63 $15 \mathrm{mM}$ & {$\left[1-{ }^{13} \mathrm{C}\right]$ pyruvic acid } & Water & $\mathbf{2 6 5 8}$ \\
\hline
\end{tabular}

\section{Conclusions}

A benzyl alcohol derivative of BDPA, $\mathbf{8}$, has been synthesized, characterized and tested as polarizing agent for fast dissolution DNP. This radical shows some advantages with respect to the commercially available BDPA, such as: a) sulfolane is avoided as the glassing agent in the sample preparation, b) better polarization levels are achieved in solid state DNP conditions and c) better ${ }^{13} \mathrm{C}$ signal NMR enhancements are reached in liquid NMR conditions. Moreover, the required polarization time has been substantially reduced by a factor of 2 when [1$\left.{ }^{13} \mathrm{C}\right]$ pyruvic acid is polarized. Additionally, it has been shown that radical $\mathbf{8}$ can be easily removed from the hyperpolarized solution in the transfer process, minimizing the loss of hyperpolarization for the presence of the paramagnetic free radical in the solution.

\section{Acknowledgements}

This research was supported by the DGI Grants "POMAs" (CTQ2010-19501) and "Be-Well" (CTQ2013-40480-R), MINECO (CTQ2012-32436), AGAUR Grant (2014SGR-0017) and MINECO Grant (PTA 2011-5037-I) for the subprogram Personal Técnico de Apoyo. We also thank the Networking Research Center on Bioengineering, Biomaterials and Nanomedicine (CIBER-BBN, Consejo Superior de Investigaciones Científicas by the JAE Grand, Amable Bernabé for his work in MALDI spectrometry. NMR studies were carried out at the joint NMR facility of the Universitat Autònoma de Barcelona and CIBER-BBN (Cerdanyola del Vallès).

\section{Notes and references}

${ }^{a}$ Institut de Ciència de Materials de Barcelona, (ICMAB-CSIC) Campus Universitari de Bellaterra, E-08193 Cerdanyola del Vallès, Spain and Networking Research Center on Bioengineering, Biomaterials and Nanomedicine (CIBER-BBN), Barcelona, Spain.

${ }^{b}$ Servei de Ressonància Magnètica Nuclear, Facultat de Ciències i Biociències, Universitat Autònoma de Barcelona, E-08193 Bellaterra, Catalonia, Spain. 
$\xi$ The radical is stable in solution at least for some hours. The intensity and shape of a freshly prepared sample solution EPR spectrum of the radical did not change 2 hours after being prepared.

Electronic Supplementary Information (ESI) available: [Synthesis and characterization of free radicals 3-8, EPR spectra of BA-BDPA, polarization build-up curves for BA-BDPA at different concentrations, removal of BA-BDPA from the dissolution, UV-Visible and EPR of inline filtered dissolution, cleaning of the polarizer dissolution line and experimental linewidths]. See DOI: 10.1039/b000000x/

1 T. Claridge, High-resolution NMR techniques in organic chemistry; 2008.

2 J. Kurhanewicz, D. B. Vigneron, K. Brindle, E. Y. Chekmenev, R. J. Deberardinis, G. G. Green, R. R. Rizi, B. D. Ross, W. S. Warren, Neoplasia, 2011, 13, 81 .

3 H. Kovacs, D. Moskau, M. Spraul, Prog. Nucl. Magn. Reson. Spectrosc., 2005, 46, 131.

4 R. Fu, W.W. Brey, K. Shetty, P. Gor'kov, S. Saha, J. R. Long, S. C. Grant, E. Y. Chekmenev, J. Hu, Z. Gan, M. Sharma, F. Zhang, T. M. Logan, R. Brüschweller, A. Edison, A. Blue, I. R. Dixon, W. D. Markiewicz, T. Cross, J. Magn. Reson., 2005, 177, 1.

5 F. Colegrove, L. Schearer, G. Walters, Phys. Rev. 1963, 132, 2561.

6 H.-U. Kauczor, R. Surkau, T. Roberts, Eur. Radiol., 1998, 8, 820.

7 S. B. Duckett, R. E. Mewis, Acc. Chem. Res., 2012, 45, 1247.

8 C. Bowers, D. Weitekamp, Phys. Rev. Lett., 1986, 57, 2645.

9 A. Abragam, M. Goldman, Reports Prog. Phys., 1978, 41, 395.

10 K. H. Sze, Q. Wu, H. S. Tse, G. Zhu, Topics in Current Chemistry; 2012, 326, pp. 215.

11 J. H. Ardenkjaer-Larsen, B. Fridlund, A. Gram, G. Hansson, L. Hansson, M. H. Lerche, R. Servin, M. Thaning, K. Golman, Proc. Natl. Acad. Sci. U. S. A., 2003, 100, 10158.

12 M. Ragavan, H.-Y. Chen, G. Sekar, C. Hilty, Anal. Chem., 2011, 83, 6054.

13 S. Bowen, C. Hilty, Angew. Chem. Int. Ed. Engl., 2008, 47, 5235.

14 H. Zeng, Y. Lee, C. Hilty, Anal. Chem., 2010, 82, 8897.

15 M. H. Lerche, S. Meier, P. R. Jensen, H. Baumann, B. O. Petersen, M. Karlsson, J. O. Duus, J. H. Ardenkjaer-Larsen, J. Magn. Reson., 2010, 203, 52 .

16 L. Frydman, D. Blazina, Nat. Phys., 2007, 3, 415-419.

17 P. Giraudeau, Y. Shrot, L. Frydman, J. Am. Chem. Soc., 2009, 131, 13902-13903.

18 M.E. Merritt, C. Harrison, C. Storey, F.M. Jeffrey, D. Sherry, C.R.Malloy, Proc. Natl. Acad. Sci. U. S. A., 2007, 104, 19773.

19 F.A. Gallagher, M. I. Kettunen, K. M. Brindle, Prog. Nucl. Magn. Reson. Spectrosc., 2009, 55, 285.

20 K. M. Brindle, S. E. Bohndiek, F. A. Gallagher, M. I. Kettunen, Magn. Reson. Med., 2011, 66, 505.

21 M. Karlsson, P. R. Jensen, J. Ø. Duus, S. Meier, M. H. Lerche, Appl. Magn. Reson., 2012, 43, 223.

22 J. H. Ardenkjaer-Larsen, I. Laursen, I. Leunbach, G. Ehnholm, L.-G. Wistrand, J. S. Petersson, K. Golman, J. Magn. Reson., 1998, 133, 1.

23 a) M. K. Kiesewetter, B. Corzilius, A. A. Smith, R. G. Griffin, T. M. Swager, J. Am. Chem. Soc., 2012, 134, 4537. b) E. L. Dane, B. Corzilius, E. Rizzato, P. Stocker, T. Maly, A. A. Smith, R. R. Griffin, O. Ouai, T. M. Swager, J. Org. Chem., 2012, 77, 1789.
24 V. K. Michaelis, A. A. Smith, B. Corzilius, O. Haze, T. M. Swager, R. R. Griffin, J. Am. Chem. Soc., 2013, 135, 2935.

25 L. Becerra, G. Gerfen, R. Temkin, D. Singel, R. Griffin, Phys. Rev. Lett., 1993, 71, 3561.

26 L. Lumata, S. J. Ratnakar, A. Jindal, M. Merritt, A. Comment, C. Malloy, A. D. Sherry, Z. Kovacs, Chem. Eur. J, 2011, 17, 10825.

27 J.C.Paniagua, V. Mugnaini, C. Gabellieri, M. Feliz, N. Roques, J. Veciana, M. Pons, Phys. Chem. Chem. Phys., 2010, 12, 5824.

28 E. L. Dane, T. Maly, G. T. Debelouchina, R. G. Griffin, T. M. Swager, Org. Lett., 2009, 11, 1871.

29 L. Lumata, M. E. Merritt, C. R. Malloy, A. D. Sherry, Z. Kovacs, J. Phys. Chem. A, 2012, 116, 5129.

30 P. Miéville, P. Ahuja, R. Sarkar, S. Jannin, P. R. Vasos, S. GerberLemaire, M. Mishkovsky, A. Comment, R. Gruetter, O. Ouari, P. Tordo, G. Bodenhausen, Angew. Chem. Int. Ed. Engl., 2010, 49, 6182.

31 M. Carravetta, O. Johannessen, M. Levitt, Phys. Rev. Lett., 2004, 92, 153003. 